\title{
PESQUISA E DESENVOLVIMENTO DE UMA \\ COLEÇÃO DE MODA SLOW FASHION
}

\author{
RESEARCH AND DEVELOPMENT OF A SLOW FASHION COLLECTION
}

\author{
TAYNARA OLIVEIRA MARTINS |UFSC \\ DANIELA ESTAREGUE ALVES, Dra. | IFSC \\ MARÍLIA MATOS GONÇALVES, Dra. | UFSC \\ CRISTIANO ALVES, Dr. |UFSC
}

\begin{abstract}
RESUMO
Uma das indústrias que mais cresce é aquela que envolve produtos de vestuário. Ao longo do século passado (1900 - 2000), o mercado desse tipo de produto tem crescido e junto dele, a competitividade foi ficando mais acirrada. No caso da moda das massas (aquelas cuja produção acontece em grande escala), utiliza-se de processos que visam a produção de peças de forma mais rápida e mais baratas. Consequentemente são também rapidamente consumidas e descartadas. A esse sistema deu-se o nome de fast fashion. Entretanto, o prejuízo socioambiental é considerável. Opondo-se a esse sistema, o movimento slow fashion, surgiu no início deste século buscando minimizar esses danos socioambientais. Este artigo apresenta o processo de criação de uma coleção de roupas desenvolvida em um projeto de conclusão de curso a partir de estratégias sustentáveis. Para tanto, além de uma pesquisa bibliográfica, foi realizada um estudo prático - a proposta de coleção. Concluise que, tal como prega o movimento slow fashion, é possível produzir peças que preconizam os princípios de sustentabilidade.
\end{abstract}

PALAVRAS CHAVE: Slow fashion; Sustentabilidade; Moda; Projeto de coleção.

\begin{abstract}
One of the fastest growing industries is that involving clothing products. Over the past century (1900-2000), the market for this type of product has grown and along with it, participation has become fiercer. No case of mass fashion (those whose production occurs on a large scale), uses processes that aim to produce parts faster and cheaper. Consequently, they are also quickly consumed and discarded. Such a system was called fast fashion. However, the socio-environmental damage is considerable. Opposing this system, the slow fashion movement emerged at the beginning of this century, seeking to cause socio-environmental damage. This article presents the process of creating a collection of clothes developed in a project to conclude a course based on sustainable strategies. In addition, in addition to a bibliographic search, a practical study was carried out - a collection proposal. Conclude that, like the slow movement of fashion, it is possible to produce pieces that advocate the principles of sustainability.
\end{abstract}

KEYWORDS: Slow fashion; Sustainability; Fashion; Project. 


\section{INTRODUÇÃO}

A história do vestuário teve início junto com o homem primitivo e desde então, evoluiu, tornando-se uma parte importante da vida em sociedade. O que era inicialmente uma maneira de se abrigar das intempéreis, passou a ser muito mais que isso. Hoje carregam signos capazes de expressar personalidade, status e até mesmo poder. O mercado da moda evoluiu, passou a influenciar mais as pessoas e a ditar como e o que devem vestir.

Ao longo dos anos o mercado foi ficando cada vez mais competitivo. Com isso, aumentou também a chamada moda das massas, ou seja, produção de roupas em larga escala e vendidas a preços acessíveis. Esse formato passou a ser chamado de fast fashion. De acordo com Paula (2015)

O conceito de Fast Fashion está relacionado com a produção voltada para o atendimento de grande número de consumidores, onde as peças são reproduzidas em larga escala para as grandes massas populacionais. Assim, as coleções são renovadas a partir dos elementos da sazonalidade e apresentação de novas tendências. (PAULA, 2015, p. 19)

Sempre inovando e se reinventando, chegando ao ponto de muitos experts acreditarem que não se está mais no fashion calendário de 4 estações, mas sim, no calendário de 52 micro estações. Com o consumo de moda que não dá sinais de desacelerar tão cedo, a moda rápida (fast fashion) só dá sinais de que aumentará ainda mais sua velocidade de produção (SINGH, 2017).

Esse método - o fast fashion, no entanto, é extremamente prejudicial ao meio ambiente e à mão de obra contratada para a produção dessas peças. Abordando este problema sob a ótica do Design sustentável, tem-se que, nos dias atuais, as empresas buscam agregar às suas marcas e produtos valores que se identifiquem com o público preocupado com o meio ambiente e o futuro do planeta.

O slow fashion, ao contrário, propõe um processo de produção menos acelerado, preocupado com questões ambientais e sociais (considerando nesse processo todo o ciclo de vida do produto - da matéria prima ao descarte). Assim, partindo do pensamento de que o slow fashion é uma saída estratégica para minimizar problemas relacionados ao ciclo de vida do produto de moda, este artigo tem como objetivo apresentar o desenvolvimento de uma coleção de moda feminina, criada com base em estratégias sustentáveis do modelo de produção slow fashion. A metodologia de projeto utilizada para a criação da coleção foi a proposta por Munari (2008).

\section{SLOW FASHION}

De acordo com Mori (2016), o slow fashion é um conceito que descende de um movimento italiano, surgido em 1986 - o slow food. Este pregava uma alimentação mais saudável, não industrializada. Baseados neste movimento, surge então o slow fashion - ou moda lenta -, que busca instigar nas pessoas um consumo mais consciente e sustentável. Fletcher e Grose (2011, p. 128) complementam afirmando que a "moda lenta requer uma infraestrutura modificada e uma produção reduzida de produtos".

Uma vez que o slow fashion prega a ideia de consumo consciente, algumas ações realizadas nas empresas de moda são consideradas por diversos profissionais de moda como sendo práticas do slow fashion. Dentre elas, o upcycling, prática em que se utiliza sobras de matéria prima (no caso tecidos) ou mesmo peças do vestuário que por algum motivo não foram vendidas para criação de novas peças. A seguir apresenta-se um pouco mais de informações sobre o upcycling.

\subsection{Upcycling}

De acordo com Wachholz e Pinheiro (2017), algumas empresas da área de moda buscam utilizar alguns métodos e estratégias que resultem em um menor impacto socioambiental, as quais podem ser utilizada em diferentes etapas do processo produtivo. As autoras desenvolveram um quadro apontando e caracterizando algumas dessas estratégias. 0 quadro 01 reproduz essas estratégias.

\begin{tabular}{|l|l|}
\hline $\begin{array}{l}\text { Open design e } \\
\text { cocriação }\end{array}$ & $\begin{array}{l}\text { Interferência dos stakeholders no desenvol- } \\
\text { vimento de produtos, com envolvimento } \\
\text { direto dos consumidores na criação. }\end{array}$ \\
\hline Customização & $\begin{array}{l}\text { Busca satisfazer as necessidades e } \\
\text { desejos do maior número de consu- } \\
\text { midores, garantindo a criação de laços } \\
\text { emocionais entre produto e cliente. }\end{array}$ \\
\hline Upcycling & $\begin{array}{l}\text { Desenvolvimento de produtos por } \\
\text { meio de sobras de tecidos e obje- } \\
\text { tos, através da reforma ou da in- } \\
\text { serção de retalhos decorativos. }\end{array}$ \\
\hline Design modular & $\begin{array}{l}\text { Criação de produtos a partir da jun- } \\
\text { ção de pequenos componentes, } \\
\text { assegurando que os consumidores } \\
\text { possam modificar seus produtos. }\end{array}$ \\
\hline Compartilhamento & $\begin{array}{l}\text { Visa à utilização de um único ar- } \\
\text { tigo por diversos indivíduos. }\end{array}$ \\
\hline
\end{tabular}

Quadro 01: Estratégias sustentáveis aplicadas à indústria do vestuário Fonte: Wachholz e Pinheiro (2017, p. 168)

Conforme pode ser percebido no quadro 01, várias são as estratégias possíveis de serem aplicadas em um projeto com vistas a um resultado com menor impacto 
ambiental. Em função das particularidades desse projeto, escolheu-se a estratégia denominada upcycling.

De acordo com a ONG Uniethos (2013), o upcycling tem como principal característica o reuso de peças de roupas prontas que podem ser adquiridas em brechós, ou outras fontes e a restauração de peças através de técnicas diversas. De acordo com o que pensa essa organização (UNIETHOS) o upcycling possibilita um aumento da vida útil dessas peças de roupa bem como a criação de novas tendo como matéria prima base as roupas que seriam 'descartadas'. Isso sem falar no valor agregado conferido às novas roupas criadas.

Em acordo com o que aponta a Uniethos (2013), Vilaca e al $(2016$, p. 4) afirmam que o upcycling é uma forma

de contribuição para se pensar em um novo uso da moda utilizando como base o consumo sustentável. Este procedimento acarreta em um prolongamento do ciclo de vida do produto, que ao invés de ser descartado, terá seu resíduo reutilizado através da criação de novas peças, muitas vezes, com maior valor simbólico, tornando-se objeto de um status mais elevado. (VILACA e al, 2016: p. 4)

Com base no exposto e, sendo justificada a escolha do upcycling como estratégia a ser adotada, parte-se, a seguir, para a apresentação do projeto desenvolvido com base nas ideias do slow fashion.

\section{O PROJETO}

A seguir o projeto da coleção de moda feminina será apresentado seguindo as etapas da metodologia proposta por Munari (2008). Para melhor encadeamento das informações, algumas etapas terão seu resultado apresentado em bloco.

A metodologia é formada por 12 etapas: Problema; Definição do problema; Componentes do problema; Coleta de dados; Análise dos dados; Criatividade; Materiais e tecnologia; Experimentação; Modelo; Verificação; Desenho de Construção e Solução.

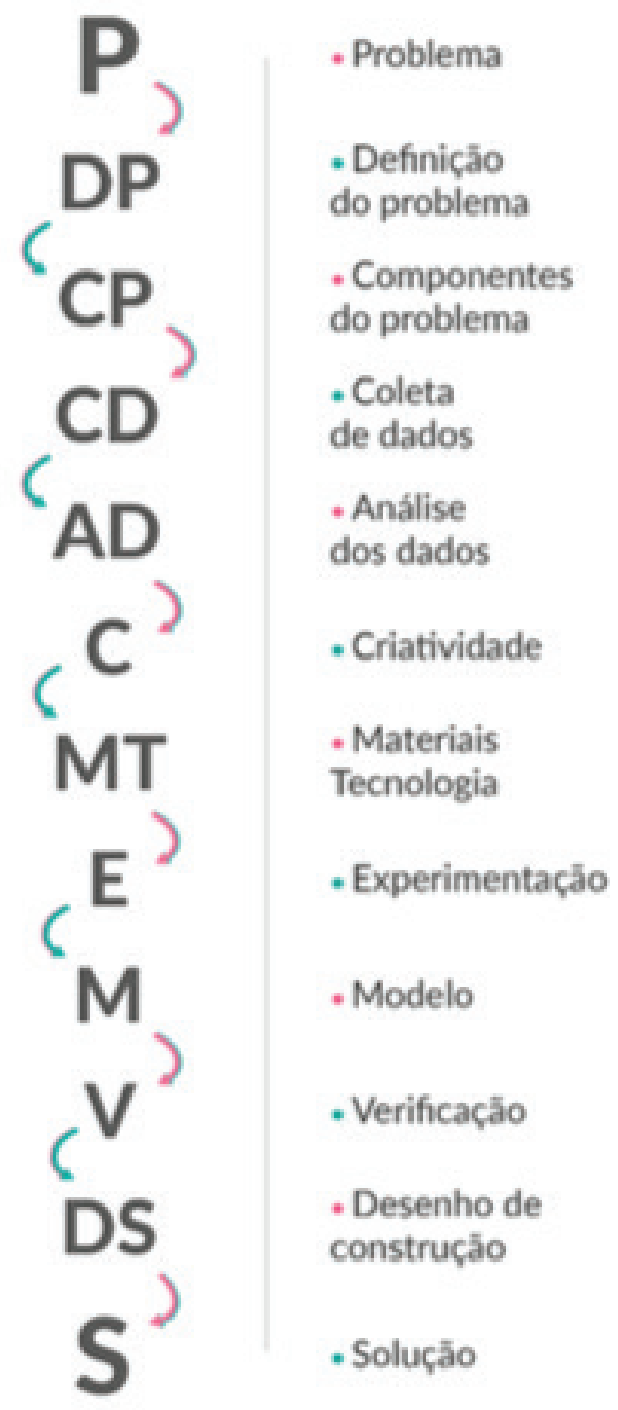

Figura 01: Metodologia de Projeto Munari (2008) Fonte: Munari (2008), adaptado pelos autores.

\subsection{Problema / Definição do problema / Componentes do problema}

Estas três etapas compreendem a definição do que se tem de problema a ser resolvido, e alguns elementos que o cercam, tais como público alvo e conceitos.

O problema de projeto pode ser definido como a criação de uma coleção de vestuário feminino composta por 10 peças, que associem princípios de sustentabilidade, os quais têm como objetivo final minimizar o impacto ambiental. Serão apresentadas o desenvolvimento de duas peças: um short e um macacão. Como componentes pode-se destacar: a definição do público-alvo; os conceitos e os recursos.

Supondo que a coleção seria realizada para uma empresa que atua no mercado de moda jovem, o nicho escolhido como público alvo é formado por mulheres pertencentes à geração $Y$ - mais comumente chamadas de 
millenials, que, de acordo com Howe e Strauss (2007) compreendem jovens nascidos entre os anos de 1982 e 2005. Deste grupo, escolheu-se mulheres que têm idade entre 18 e 25 anos para o nicho da coleção aqui apresentada.

De acordo com Carvalho (2017, p. 16), os millenials "foram os primeiros indivíduos parte de uma geração a nascerem em um mundo globalizado e interligado", ou seja, desde crianças já tiveram contato com aparatos tecnológicos. Pode-se dizer ainda que:

Por terem nascido em um período em que o mundo apresentava maior estabilidade política e econômica, sem a ocorrência de guerras e fortes crises nas economias dos países, a família pôde se manter mais unida e dar maior atenção às crianças [...]. Tornaram-se adultos mais otimistas em relação ao futuro, acreditando que seus objetivos almejados serão alcançados. CARVALHO (2017, p. 18)

Contudo, esses jovens, desde muito cedo já necessitam fazer escolhas que podem decidir seu futuro. Mas ao mesmo tempo "querem experimentar tudo o que a vida pode lhes proporcionar durante esse período de juventude." CARVALHO (2017, p. 18)

Com base nesses ideais foram definidos três conceitos da coleção: experiência; único e atemporal. O conceito "experiência" foi escolhido por que a ideia de experienciar as coisas que a vida apresenta é uma concepção forte dos millennials. Esses jovens de 18 a 25 anos, muitas vezes em idade universitária estão constantemente à procura do novo e do diferente. Eles querem experimentar e fazer parte de algo maior, com uma história a ser contada.

O segundo conceito: "único", complementa o conceito anterior. A experimentação resulta em vivências, ou seja, ao experienciar o mundo que os cerca, os jovens buscam extrair delas vivências únicas que, além de expressar sua personalidade e acima de tudo diferenciar-se dos demais.

O terceiro conceito foi elaborado tendo como referência elementos que remetem à sustentabilidade. A palavra escolhida para representar esse conceito é "atemporal" complementa a ideia de que, o que é atemporal, nunca sai da moda. Peças de roupa atemporais podem ser usadas por muito tempo, ou seja o ciclo de vida dessas roupas extrapola o que é ditado no modelo fast fashion. Além disso, pode-se dizer que transparecem a personalidade do dono, sua individualidade, complementando assim o conceito "único". A roupa é vestida não para pertencer a um grupo ou se encaixar em algum padrão, mas sim expressar uma personalidade, uma individualidade.

\subsection{Coleta de dados / Análise de dados}

Definidos o público alvo e os conceitos da coleção, passa-se para as etapas de coleta e análise dos dados.

Sendo a geração conhecida como millennial o público alvo deste projeto, buscou-se conhecê-lo melhor. Complementando o que foi apresentado no item 3.1, Simões e Gouveia, (2008) apresentam um conjunto de traços que caracterizam as pessoas nascidas nesta geração. $\mathrm{O}$ quadro 02 , a seguir apresenta esses traços, bem como sua descrição.

\begin{tabular}{|c|c|}
\hline Traço & Descrição \\
\hline espacial & $\begin{array}{l}\text { porque desde o início dos anos } 80 \text { tem havido uma } \\
\text { grande preocupação com questões juvenis, a mídia tem } \\
\text { prestado muita atenção a assuntos relacionados às ge- } \\
\text { rações mais jovens: a geração do milênio percebe essa } \\
\text { preocupação global com eles. }\end{array}$ \\
\hline protegido & $\begin{array}{l}\text { esta é a primeira geração de sinais de "bebê a bordo" e } \\
\text { "assentos de carro para bebês" especiais }\end{array}$ \\
\hline Confiante & $\begin{array}{l}\text { a geração do milênio acredita que será melhor do que } \\
\text { seus pais quando atingirem a mesma idade }\end{array}$ \\
\hline $\begin{array}{l}\text { Atuação em } \\
\text { grupo }\end{array}$ & $\begin{array}{l}\text { a geração do milênio exibe um comportamento forte- } \\
\text { mente orientado ao grupo e é muito propensa a parti- } \\
\text { cipar de atividades em grupo }\end{array}$ \\
\hline Convencional & $\begin{array}{l}\text { esta é uma geração que tende a estar em conformida- } \\
\text { de com os valores dos pais }\end{array}$ \\
\hline Pressionado & $\begin{array}{l}\text { Sua vida é toda "programado" - eles têm horários de } \\
\text { jogo, praticam esportes, têm aulas de música e ainda } \\
\text { precisam responder muitas mensagens de correio e } \\
\text { mensagens instantâneas }\end{array}$ \\
\hline Conquistas & $\begin{array}{l}\text { desde os primeiros anos do ensino médio, as crianças } \\
\text { dessa geração já pensaram seriamente em formação, } \\
\text { empregos e salários }\end{array}$ \\
\hline
\end{tabular}

Quadro 02: Traços da Geração millennial

Fonte: Simões e Gouveia, (2008, p. 6) - tradução livre

Foram também pesquisadas marcas similares. São marcas de roupas que guardam algum tipo de conexão com as ideias da coleção pretendida.

O quadro 03 apresenta uma síntese informática das marcas concorrentes.

\begin{tabular}{|l|l|}
\hline Marca & Características principais \\
\hline Karmen & $\begin{array}{l}\text { - tiragem limitada } \\
\text { - reaproveitamento de tecidos } \\
\text { - não segue modismos } \\
\text { - processo de produção invertida }\end{array}$ \\
\hline $\begin{array}{l}\text { Gioconda } \\
\text { clothing }\end{array}$ & $\begin{array}{l}\text { - usa tecidos e acabamentos naturais } \\
\text {-valoriza o conforto } \\
\text { - evita desperdícios } \\
\text { - produção justa e artesanal } \\
\text { - abrangem tamanhos PP ao EXG } \\
\text { - relação mais próxima com o consumidor }\end{array}$ \\
\hline AhIma & $\begin{array}{l}\text { - peças contemporânea, mini- } \\
\text { malistas e extravagantes } \\
\text { - roupas são feitas para durar } \\
\text { - processo de produção invertida }\end{array}$ \\
\hline
\end{tabular}




\begin{tabular}{|l|l|}
\hline $\begin{array}{l}\text { AhIma (con- } \\
\text { tinuação) }\end{array}$ & $\begin{array}{l}\text { - reaproveitamento é o ponto de partida } \\
\text { - utilização de materiais orgânicos, biodegradáveis } \\
\text { e reciclados }\end{array}$ \\
\hline Doisélles & $\begin{array}{l}\text { - trabalha com tricô manual } \\
\text { - usa sua produção como processo de reinserção } \\
\text { social de presidiários }\end{array}$ \\
\hline Nicole & $\begin{array}{l}\text { - peças são vegan friendly e 100\% brasileiras } \\
\text { - proporcionar bem-estar através de produtos de } \\
\text { boa qualidade } \\
\text { - produtos atemporais e confortáveis } \\
\text { - produção em pequenas quantidades } \\
\text { - peças democráticas, sendo grande parte unissex }\end{array}$ \\
\hline Cycleland & $\begin{array}{l}\text { - características das coleções } \\
- \text { não se baseiam em tendência de moda } \\
\text { - fazem peças atemporais } \\
\text { - coleção é limitada a poucas unidades } \\
- \text { utilizam algodão com elastano } \\
-100 \% \text { vegana } \\
\text { - não tem descarte de matéria-prima }\end{array}$ \\
\hline
\end{tabular}

Quadro 03: Marcas similares

Fonte: Autores

Como forma de organizar melhor as informações coletadas e analisadas, foram elaborados, a partir da ferramenta mapa de empatia. De acordo com Marques (2018), o mapa de empatia é uma ferramenta desenvolvida pela empresa de consultoria americana Xplane. Seu objetivo é facilitar a organização de informações acerca de uma pessoa, com o intuito de visualizar seus desejos e necessidades. Algumas personas que representam o perfil do público alvo millennial. (figuras 02 e 03)

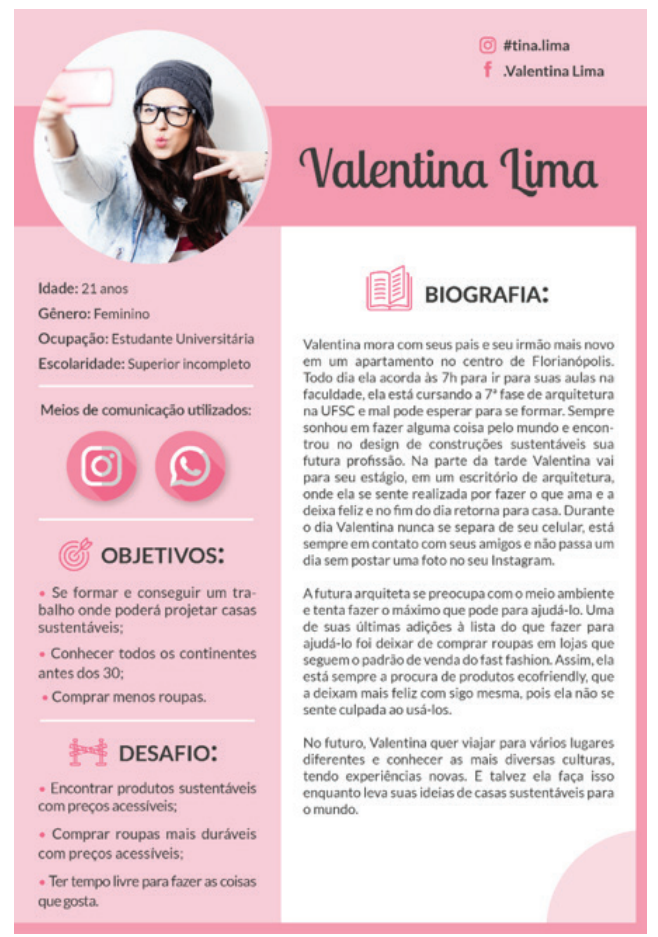

Figura 02: Perfil persona Valentina Lima. Fonte: Autores

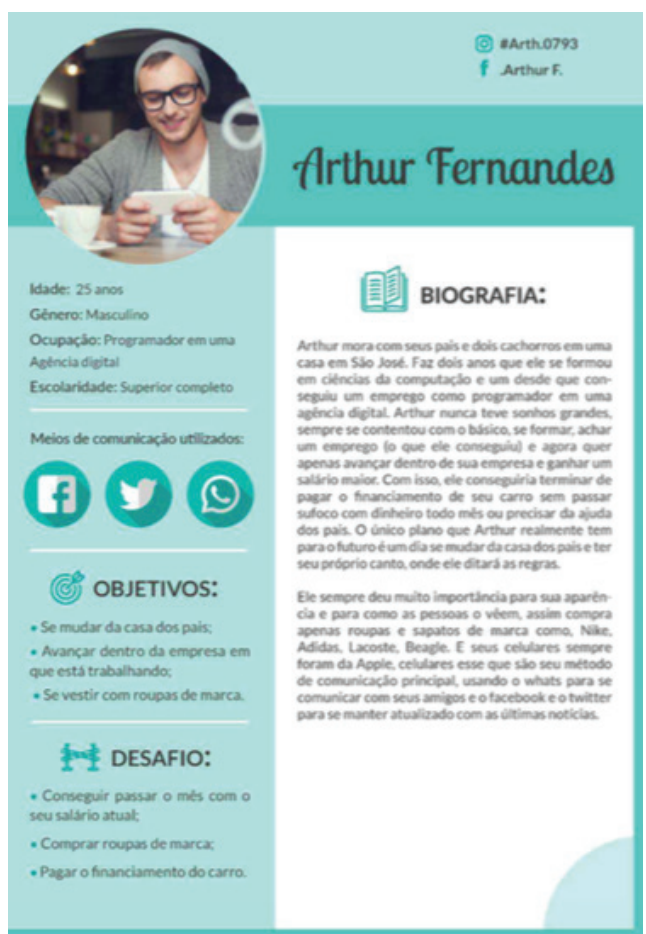

Figura 03: Perfil persona Arthur Fernandes. Fonte: Autores

\subsection{Criatividade/Materiais e tecnologia/Verificação}

Tendo já esclarecido qual é o público alvo ao qual se destina a coleção (geração millennial), conhecendo seus conceitos (único, experiência e atemporal) e ainda um panorama das marcas similares, parte-se para a etapa de criação. Aqui devem ser geradas as alternativas. Juntamente a essa etapa são também especificados os materiais e as tecnologia a serem utilizadas na confecção das peças.

Com o intuito de criar a coleção a partir de estratégias sustentáveis, nestas etapas (criatividade; materiais e tecnologia e verificação) resolveu-se adotar o modelo de produção invertida. Esse modo de produção foi encontrado em duas marcas similares (Karmen e Ahlma). Ele se caracteriza por somente iniciar a etapa criativa do projeto após definir os materiais. A figura 04 mostra uma breve comparação entre esse modelo e o modelo tradicional.

PRODUÇÃO NORMAL

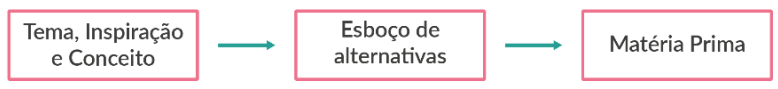

PRODUÇÃO INVERTIDA

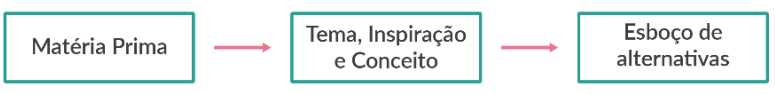

Figura 04: Modelos de produção. Fonte: Autores 
Sobre a matéria prima, serão descritas aqui somente as que irão compor as peças 8 e 10 (apontadas na figura 12). São elas:

a) Jeans - mesmo conhecendo-se o processo produtivo da obtenção deste tecido e concluindo-se que este gera impacto ambiental durante o processo, optou-se por sua escolha devido ao fato de que o jeans a ser utilizado nesta coleção é resultado de aproveitamento de sobras de uma grande empresa de confecção de roupas. Especialmente para esse projeto, buscou-se, baseado nas ideias da estratégia upcycling, usar tecido que seria descartado por grandes empresas. Assim sendo, usou-se o tecido que seria descartado por uma empresa e foi doado para este projeto. Sua escolha se deveu pela associação que o jeans tem com a ideia de "atemporalidade" - um dos conceitos da coleção. É um tecido que nunca sai de moda.

Botões, patch, broches - essas peças caracterizam doação de empresas de aviamentos que não seriam mais utilizados por ela em suas criações. Quanto aos botões, etiquetas adesivas (patch), sua escolha se adequa bem ao conceito "único"

A figura 05 mostra os materiais escolhidos para as peças 8 e 10 (camisão e macacão jeans)

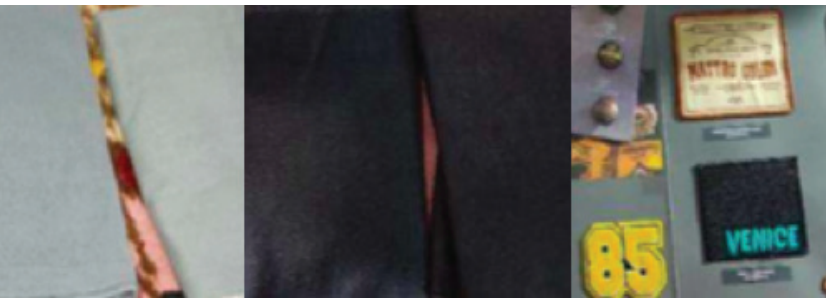

Figura 05: Materiais Fonte: Autores.

Esses dois são a matéria prima principal das duas peças da coleção que serão detalhadas mais a frente. Com isso, parte-se para a criação (definição do tema e geração de alternativas).

Escolheu-se como tema "slow down", ou seja desacelere. Curta mais a sua vida. A inspiração é: "pequenos momentos de prazer" que pode ser representado pela palavra conceito "ócio". A figura 06 apresenta o painel de apresentação do tema.

Uma vez definido o tema, chega o momento de coletar imagens que possam auxiliar o designer na hora de criar. Esses painéis têm um papel importante no processo, pois podem inspirar associações entre os conceitos da coleção (único, experiência e atemporal), o tema da coleção (slow down) com o público alvo da coleção (millennials). Foram desenvolvidos dois painéis com imagens que representam um pouco da história da moda, com peças que marcaram época e ainda continuam na moda, marcando assim atemporalidade e unicidade. Muitas das imagens ainda representam momentos da vida das pessoas, expressando assim a experiência. As figuras 07 e 08 apresentam esses painéis.

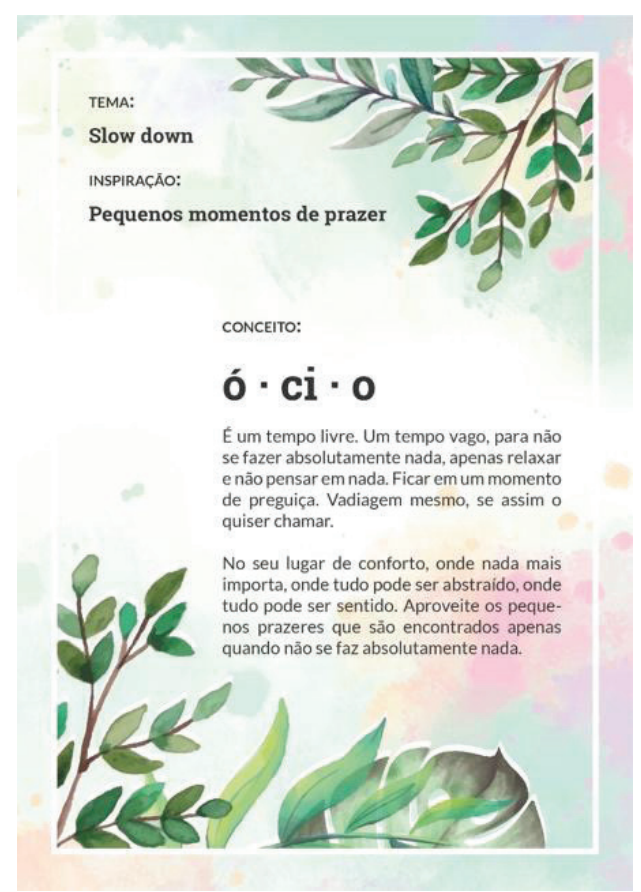

Figura 06: Painel de apresentação do tema.

Fonte: Autores.

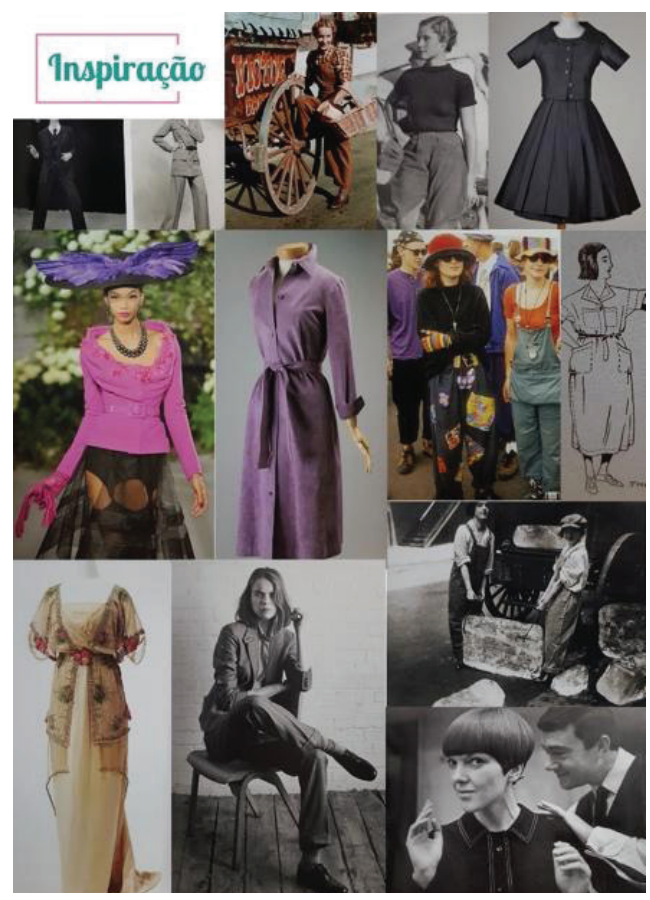

Figura 07: Painel de apresentação do tema Fonte: Autores. 


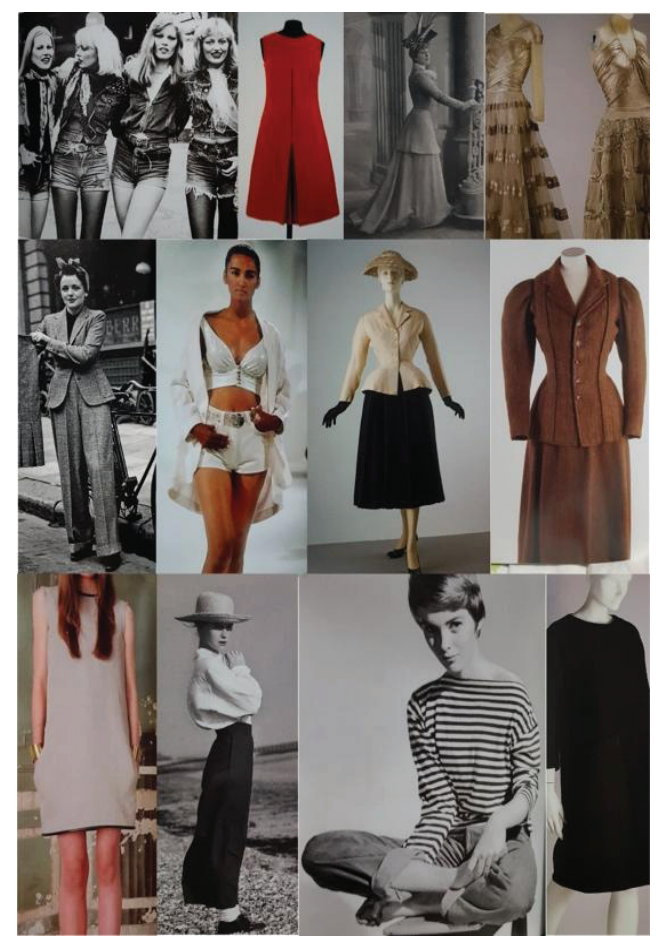

Figura 08: Painel de apresentação do tema Fonte: Autores.

Antes de iniciar a geração de alternativas foi decido que a coleção seria composta por saias, camisetas, vestido, shorts. As figuras 09, 10 e 11 mostram alguns dos croquis das alternativas criadas.

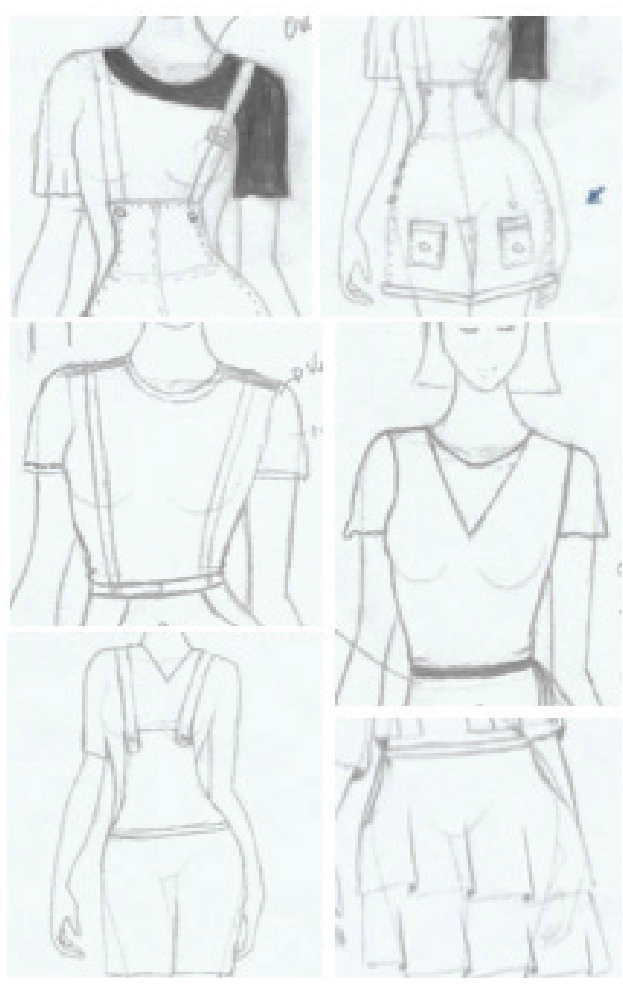

Figura 09: Alternativas para a coleção Fonte: Autores.

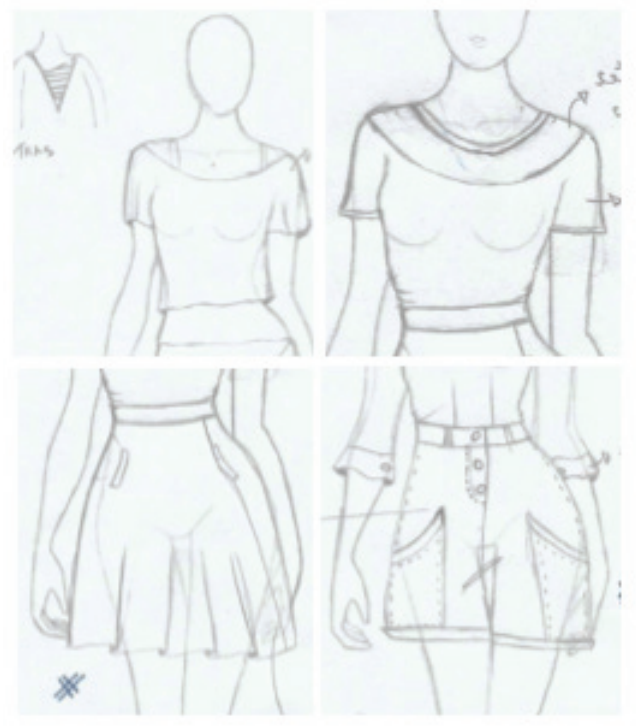

Figura 10: Alternativas para a coleção Fonte: Autores.

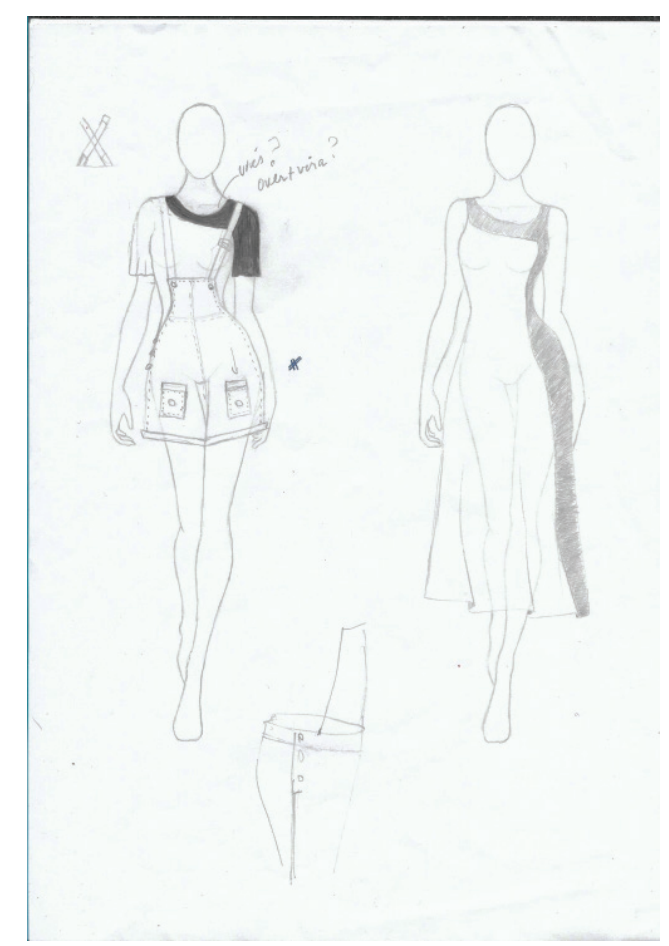

Figura 11: Alternativas para a coleção Fonte: Autores.

Desenvolvidas as alternativas, das quais destacamos as apresentadas nas figuras 09, 10 e 11, foi necessário fazer a escolha daquelas que fariam parte da coleção. Para tanto, utilizou-se uma ferramenta chamada matriz de decisão. Segundo Pazmino (2015, p. 222), a

matriz de decisão busca facilitar a escolha da melhor alternativa de solução [...] serve para medir a capacidade de cada solução de atender aos requisitos previamente estabelecidos. 
Essa ferramenta - a matriz de decisão - é comumente utilizada na área de design para o processo de tomada de decisão em diferentes etapas do processo de projeto. Para este projeto, ela foi utilizada para a escolha, dentre os croquis criados, daqueles que formariam a coleção. Para tanto, foram definidos quatro critérios de escolha, os quais se basearam nos conceitos da coleção e nos materiais disponíveis, Assim, os critérios definidos foram: Experiência, Único e Atemporal (baseados nos conceitos da coleção) e Materiais (ou seja, que a peça fosse possível de ser confeccionada com os materiais disponíveis, os quais deveriam ser pouco impactantes, vindo de encontro com as ideias do upcycling). Para a pontuação dos critérios foi utilizada uma escala que variou de 1 até 3 . A escolha dos valores observou o seguinte raciocínio: se um critério não é atendido, a ele é atribuída a nota mais baixa (1); se um critério é atendido em parte, a ele é atribuída a nota média (2) e, se um critério é plemanemte atendido, a ele é atribuída a nota maior (3). Para se ter uma ideia de como se deu a aplicação da matriz de decisão, apresenta-se o quadro 04, que mostra quatro das 10 peças escolhidas.
Depois de analisar os resultados da matriz de decisão, as peças foram organizadas em função da pontuação recebida. Ao se analisar os 10 croquis que receberam maior pontuação total, percebeu-se que compunham um conjunto de looks variados. A quantidade (10) já havia sido definida na etapa inicial do projeto (apresentada no item 3.1 deste artigo)

- Short jeans de cintura alta

- Saia godê de cintura alta preta

- Saia godê de cintura alta de amarrar

- Vestido duas camadas

- Blusa jeans

- Camiseta invertida

- Camisão jeans

- Blusa de alça

- Camiseta malhada

- Macacão jeans

A figura 12 mostra os croquis escolhidos.

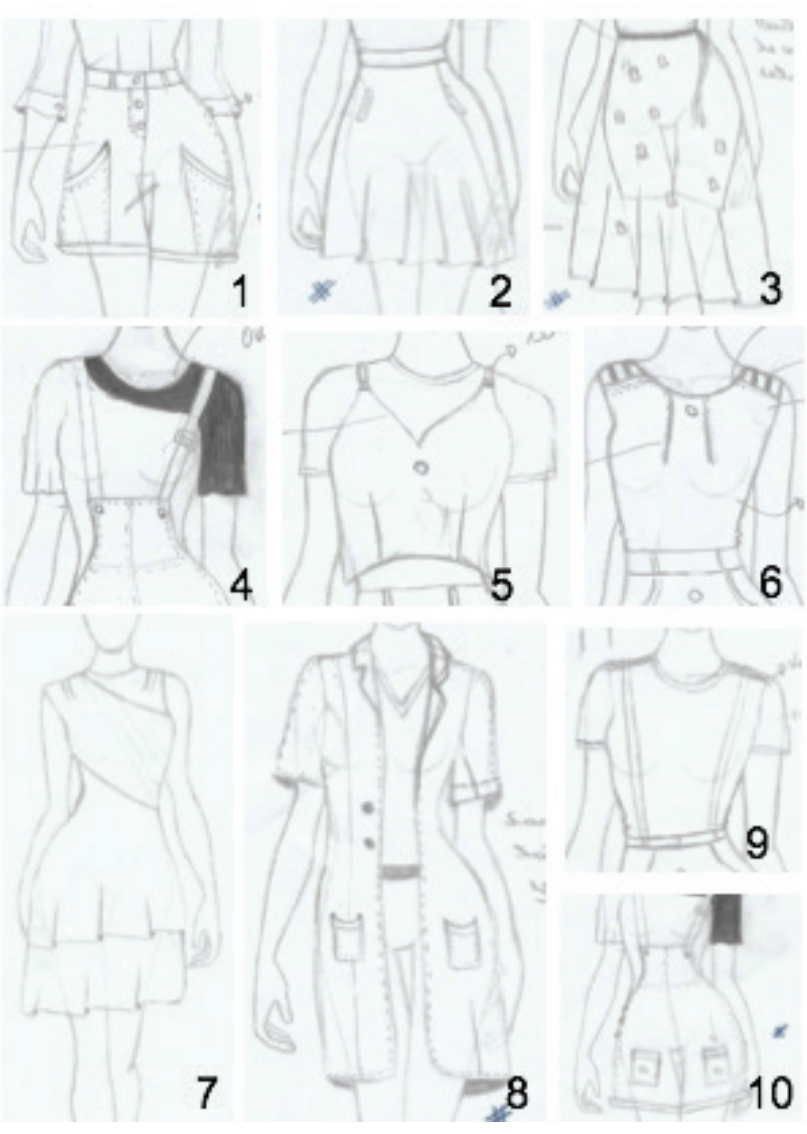

Figura 12: Peças escolhidas para a coleção. Fonte: Autores.

Uma vez que o objetivo deste artigo é apresentar o processo de criação de uma coleção, a partir de estratégias sustentáveis, serão apresentadas a seguir somente duas das peças que compõem a coleção: peças 8 (camisão jeans) e 10 (macacão jeans). 
A verificação é o momento em que a ideia pensada - neste caso, os croquis - são factíveis, ou seja, possíveis de serem produzidos. Neste momento constatou-se que as ideias criadas (representadas nos croquis) eram condizentes com os tecidos escolhidos (jeans). Os aviamentos definidos (botões, etiquetas) eram também compatíveis e o maquinário disponível (máquinas de costura) e a experiência das costureiras em trabalhar com esses materiais são também condizentes com o que foi proposto. Com isso, é possível partir para o desenho final e finalização do projeto.

\subsection{Desenho final / Solução}

Com base na metodologia de Munari (2008), parte-se para o desenho final. No caso de um produto de moda, o desenho final se materializa nos moldes das peças a serem confeccionadas. Para tanto, houve análise mais detalhadas dos croquis e posterior elaboração dos moldes para que estes resultassem em peças realmente possíveis de serem "vestidas". (figuras 13 e 14)
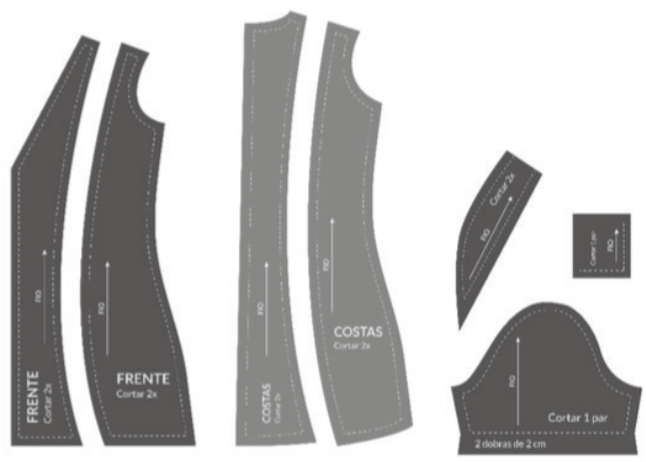

Figura 13: Moldes camisão jeans Fonte: Autores.
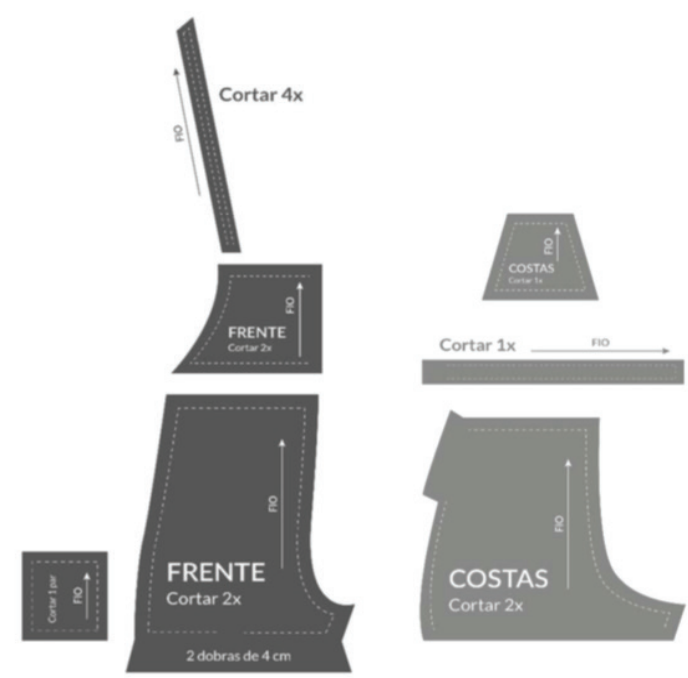

Figura 14: Moldes macacão jeans Fonte: Autores.
Além dos moldes, as fichas técnicas das peças da coleção são muito importantes. Elas são um recurso comunicacional entre o designer ou estilista e o setor produtivo. Em uma ficha técnica estão dispostas além de uma representação gráfica da peça em escala reduzida - um desenho técnico de moda - informações sobre a matéria prima (tecido e outros elementos, tais como aviamentos), tamanho do manequim, quantidade de tecido, custos, tipos de costura, dentre outras. Elas são importante aliada na garantia do produto final dentro do prazo e com a qualidade esperada. As figuras 15 e 16 apresentam a ficha técnica do camisão e do macacão jeans.
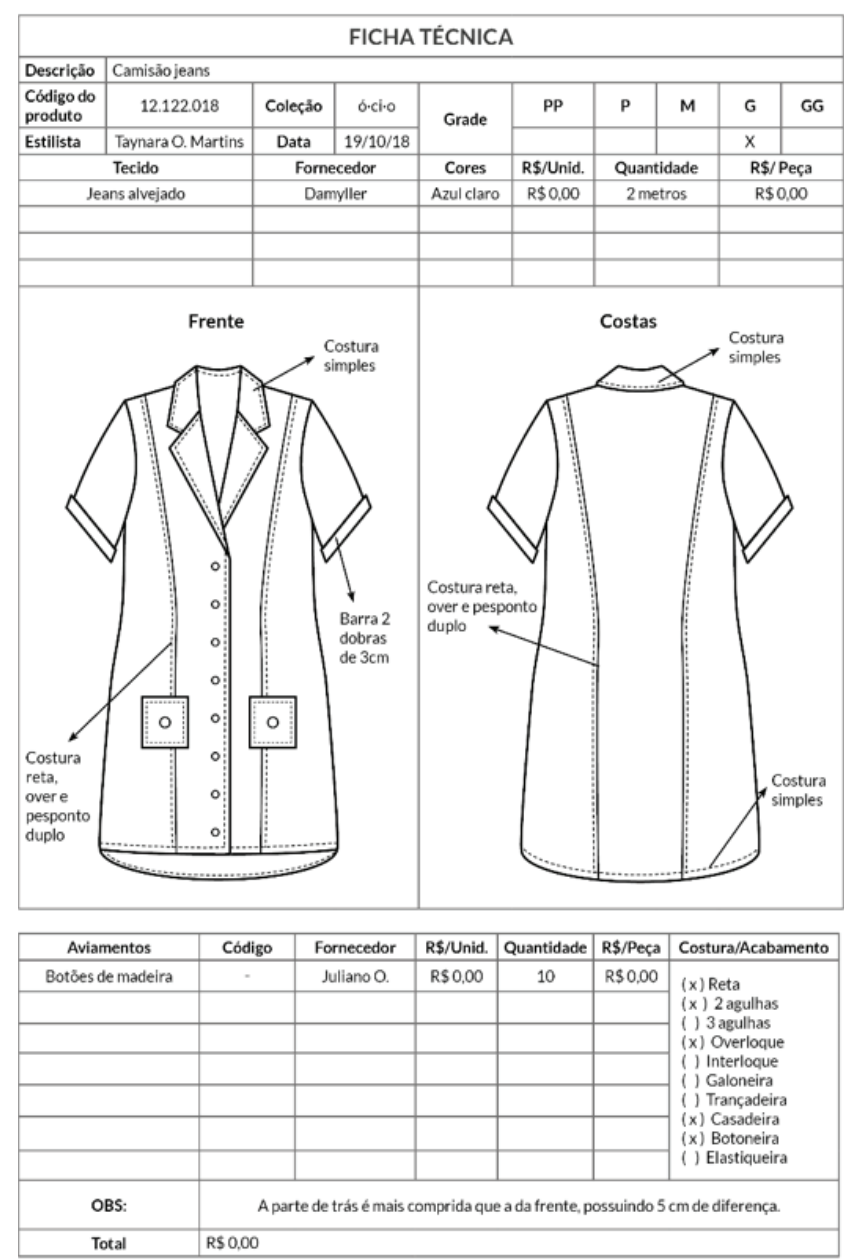

Figura 15: Ficha técnica do camisão jeans Fonte: Autores. 


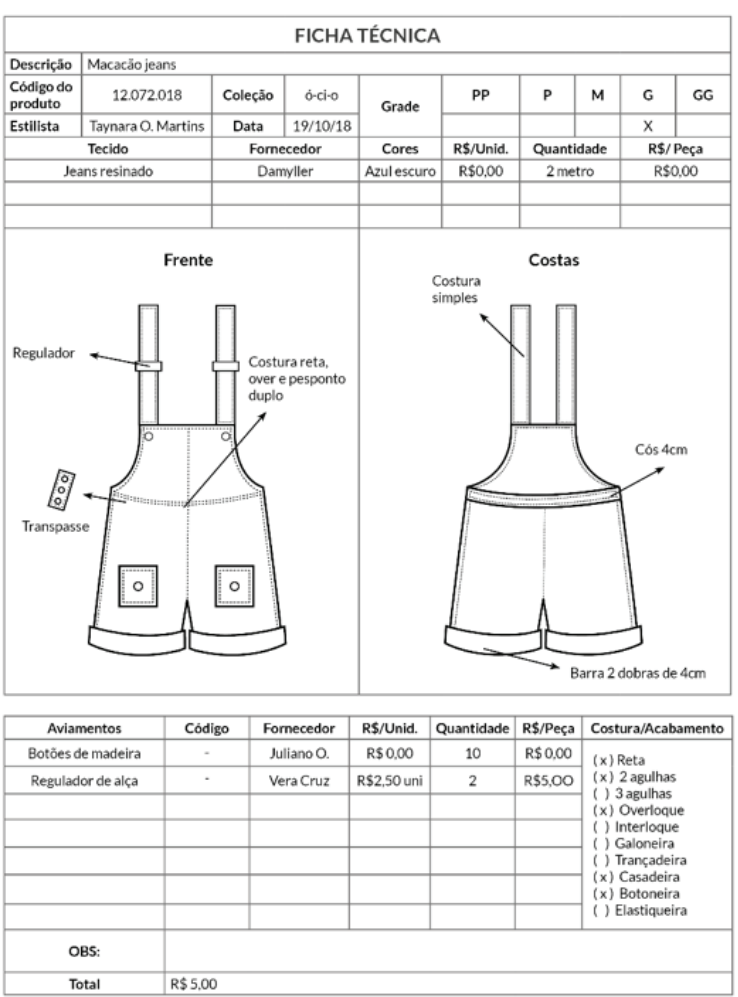

Figura 16: Ficha técnica do macacão jeans Fonte: Autores.

Concluído o detalhamento das peças, as mesmas foram entregues à costureiras para serem confeccionadas. Após encerradas todas as etapas de confecção (corte, costura, arremates, aplicação de aviamentos) as peças da coleção (duas delas: 8 e 10) estão prontas e podem ser vistas nas figuras 17 e 18.

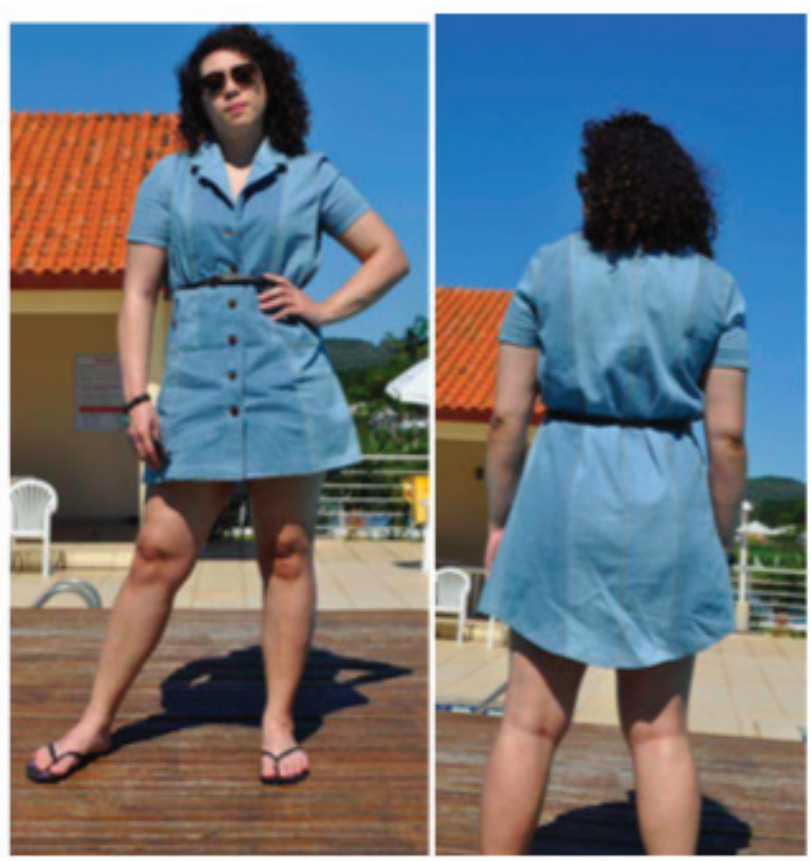

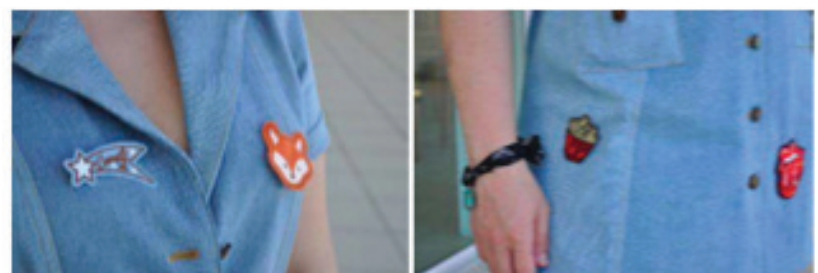

Figura 17: Camisão jeans

Fonte: Autores.
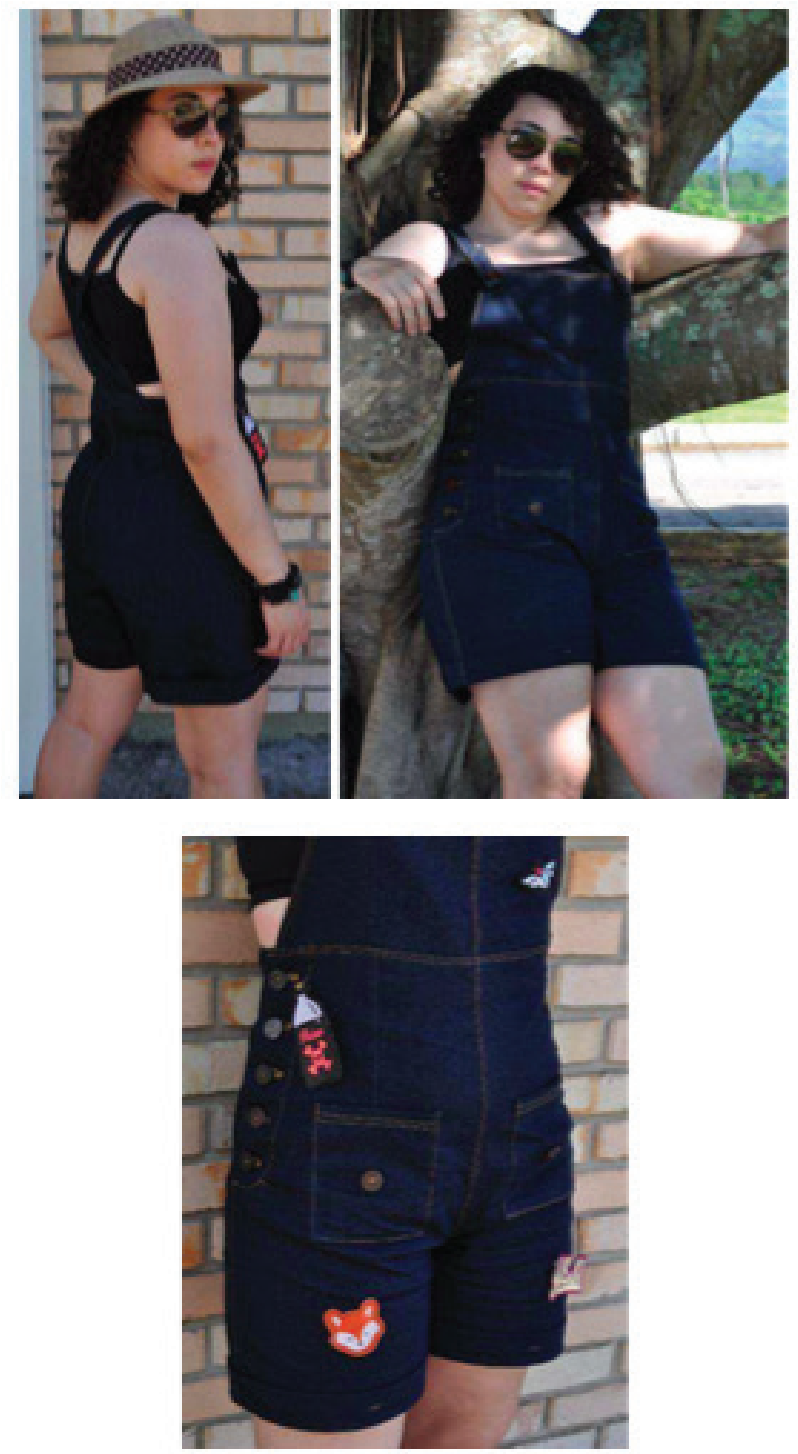

Figura 18: Macacão jeans Fonte: Autores

Como em um processo de confecção é praticamente inevitável a sobra de tecidos, pretende-se criar peças acessórios com essas sobras. Podem ser criadas faixas, lenços, cintos e assim aproveitar ao máximo os materiais.

Concluídas as peças da coleção, das quais duas são apresentadas neste artigo, buscou-se uma maneira de apresentá-las dando ênfase à ideia do consumo consciente. 
Decidiu-se então criar uma estratégia de comunicação para implementação a curto prazo (inclusão de uma tag que incentiva um consumo consciente) e a médio/longo prazo (uma etiqueta que informa o crédito carbono do produto).

A tag foi criada como uma forma de conscientizar os consumidores sobre o que é o movimento slow fashion, qual a sua importância no cenário de consumo atual e sobre o impacto positivo que pode causar no meio ambiente. Nessa tag podem ser vistas informações simples que procuram instigar a curiosidade do consumidor sobre o assunto. A figura 19 apresenta a tag criada.

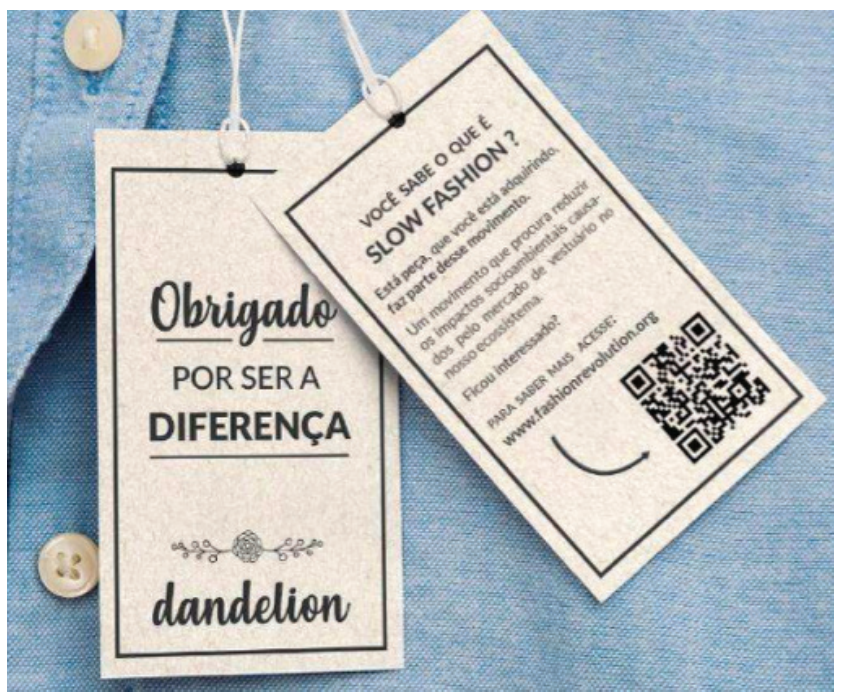

Figura 19: Ficha técnica do camisão jeans Fonte: Autores.

A etiqueta interna da peça, além de apresentar as informações previstas na legislação vigente (tamanho, composição do tecido, forma de conservação da peça, dentre outras) apresenta também informação relativa a crédito carbono.

De acordo com informações disponíveis no site do Ministério do Meio Ambiente, o Protocolo de Quioto, criado em 1997, entrou em vigor no ano de 2005. Tratase de um tratado Complementar à Convenção-Quadro das Nações Unidas sobre Mudança do Clima. Nele foram definidas metas de redução de emissões de gases de efeito estufa (GEE). Alguns mecanismos para essa diminuição foram criados. Dentre eles, o MDL (Mecanismo de Desenvolvimento Limpo), que diz:

um país desenvolvido ou de economia em transição para o capitalismo pode comprar "créditos de carbono", denominados "reduções certificadas de emissões" (RCEs) resultantes de atividades de projeto desenvolvidas em qualquer país em desenvolvimento que tenha ratificado o Protocolo. (BRASIL, 2020, s/p)
Complementando essa informação, Silva e Macedo (2012, p. 1656) colocam que:

os projetos de MDL podem envolver substituição de energia de origem fóssil por outras de origem renovável, racionalização do uso da energia, atividades de florestamento e reflorestamento, serviços urbanos mais eficientes, entre outras possibilidades.

O Brasil participa deste mercado. Assim, uma meta é a inclusão de etiquetas que informem os impactos evitados das peças, ou seja, a quantidade de gases que não foram emitidos em função reuso de tecidos na confecção. A figura 20 mostra a etiqueta pensada para informar o consumidor sobre o crédito carbono.

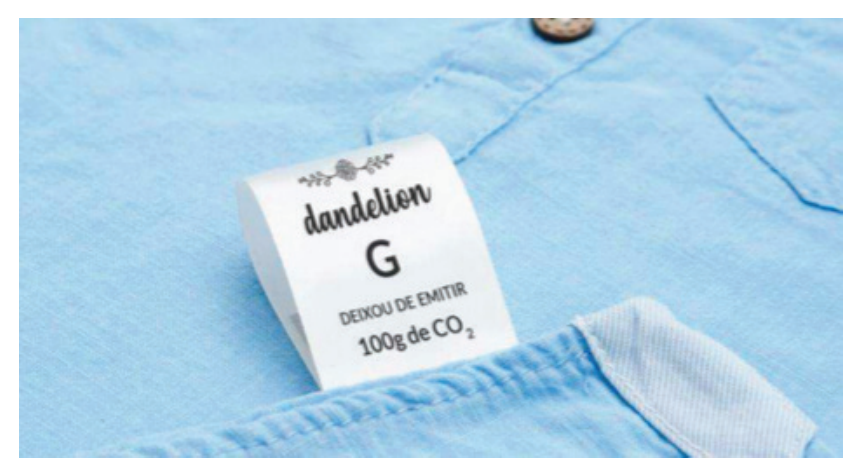

Figura 20: Etiqueta crédito de carbono. Fonte: Autores.

\section{CONSIDERAÇÕES FINAIS}

O desenvolvimento da coleção possibilitou uma análise de como funciona o mercado da moda e especialmente o produto de moda pensado através de um olhar mais atual. Assim, foi apresentado um breve conceito sobre o que é o slow fashion, uma alternativa sustentável, que agrega mais valor a todo o processo de produção de moda (neste caso vestuário).

Identificou-se também o público-alvo a quem esse projeto será destinado, jovens adultos que se encaixam dentro da geração millennials. O perfil do público foi pesquisado e analisado, e notou-se que esta faixa etária é uma das que mais se preocupa com o meio-ambiente e gostaria de fazer algo para melhorá-lo, ao mesmo tempo, também se mostram uma grande força de compra no mercado consumidor, estando ainda em uma faixa etária que pode ser educada e ensinada quanto aos benefícios do slow fashion.

Por fim, ao se fazer reuso de materiais percebe-se que é possível serem confeccionadas roupas, cujo processo não seja tão agressivo ao meio ambiente. 


\section{REFERÊNCIAS}

BRASIL, Governo do. Entenda como funciona o mercado de crédito de carbono. 2017. Disponível em: <http://www.brasil.gov.br/noticias/meio-ambiente/2012/04/entenda-como-funciona-o-mercado-de-credito-de-carbono>. Acesso em: 28 out. 2018.

BRASIL. Ministério do Meio Ambiente. Protocolo de Quioto. 2020. Disponível em: https://www.mma.gov. br/clima/convencao-das-nacoes-unidas/protocolo-de-quioto.html. Acessado em 06 jun 2020.

CARVALHO, Nathália Cristina de Oliveira. Millennials: quem são e o que anseiam os jovens da geração Y. 2017. 47 f. Trabalho de Conclusão de Curso (Graduação) - Universidade Federal do Rio de Janeiro. Rio de Janiero. 2017. Disponível em: https://pantheon. ufrj.br/bitstream/11422/4865/1/Monografia\%20-\%20 Nathalia\%20Carvalho.pdf. Acesso em: 11 jun. 2020. FLETCHER, Kate e GROSE, Lynda. Moda e sustentabilidade: design para a mudança. São Paulo: Senac, 2012.

HOWE, N. e STRAUSS, W. (2007). The next 20 years - How customer and workforce attitudes will evolve. Harvard Business Review, Julho-Agosto, 2007. Disponível em https://hbr.org/2007/07/the-nex-will-evolve. Acesso em: 11 maio 2020.

MARQUES, José Roberto. Saiba o que é mapa de empatia e sua importância para empreendedores. 2018. Disponível em: <https://www.ibccoaching.com. br/portal/saiba-o-que-e-mapa-de-empatia-e-sua-importancia-para-empreendedores/>. Acesso em: 15 jun. 2018

MORI, Natália Tinoco. Slow Fashion: conscientização do consumo de moda no Brasil. 2016. 46 f. Trabalho de Conclusão de Curso (Especialização). Universidade de São Paulo. São paulo, 2016. Disponível em: http:// www2.eca.usp.br/moda/monografias/NATALIA\%20 MORI-USP.pdf. Acesso em: 15 jun. 2020.

MUNARI, Bruno. Das Coisas Nascem Coisas. 2. ed. São Paulo: Martins Fontes, 2008.

PAULA, Gabriela Pegos de. A evolução da moda mediante os conceitos de fast fashion e slow fashion. 2015. 137 f. Trabalho de Conclusão de Curso (Graduação) - Universidade Federal Tecnológica do Paraná. Apucarana. 2015. Disponível em http://repositorio.roca.utfpr.edu.br/jspui/bitstream/1/10969/1/ AP_CODEM_2015_2_07.pdf. Acesso em 21 jul 2020.

PAZMINO, Ana Verônica. Como se cria: $\mathbf{4 0}$ métodos para design de produtos. São Paulo: Blucher, 2015.

SILVA, Luciano Ferreira da. MACEDO, Amanda Helena. Um estudo exploratório sobre o crédito de carbono como forma de investimento. in: Revista Eletetrônica em Gestão, Educação e Tecnologia Ambiental. v(8), n॰ 8, p. 1651-1669, SET-DEZ, 2012. SIMÕES, L. e GOUVEIA, L. (2008). Targeting the Millennial Generation. III Jornadas de Publicidade e Comunicação. A Publicidade para o consumidor do Séc. XXI. UFP. Porto. 10 de Abril. Disponível em: http:// homepage.ufp.pt/lmbg/com/Isimoes1_sopcom08. pdf. Acesso em: 26 maio 2020.

SINGH, Ganit. Fast Fashion Has Changed the Industry and the Economy. 2017. Disponível em: <https://fee. org/articles/fast-fashion-has-changed-the-industry-and-the-economy/>. Acesso em: 20 mar. 2018.

UNIETHOS. Sustentabilidade e competitividade na cadeia da moda. São Paulo, maio de 2013.

VILACA, Débora Barbosa Guedes de Oliveira. ARAÚJO, Angélica Catarine de Mota. OLIVEIRA, Alanne, Laniely Nunes de. GUIMARÃES, Steven Santos. BEZERRA, Paloma Rayanne Silva. Upcycling e sustentabilidade: o despertar da indústria da moda para logística reversa. In: Anais do XXXVI Encontro Nacinal de Engnharia de Produção. João Pessoa, 03 - 05 de outubro de 2016. WALCHHOLZ, Larissa Aparecida. PINHEIRO, Eliane. Estratégias sustentáveis de moda: um estudo aplicado ao desenvolvimento de produtos de vestuário. In: Mix Sustentável | Florianópolis | v.3 | n.4 | p.157172 | nov. | 2017. Disponível em: http://ojs.sites.ufsc.br/ index.php/mixsustentavel/article/view/2312. Acesso em: 11 maio 2020. 


\section{AUTORES}

ORCID ID: https://orcid.org/0000-0003-1473-3160

TAYNARA OLIVEIRA MARTINS | Universidade Federal de Santa Catarina - UFSC-Curso: Design | Endereço: Rua Maria Julia da Luz, no 970 - Jardim Cidade de Florianópolis, São José - SC | CEP: 88111-300, Brasil | e-maill: tayolivera@hotmail. com

ORCID ID: https://orcid.org/0000-0003-3584-6455

DANIELA ESTAREGUE ALVES, Dra. | IFSC - Palhoça Bilíngue Curso: Design | Endereço: R. Santos Saraiva, 739 - Apto 101 - Estreito - Florianópolis/SC - 88070-100, Brasil. | e-maill: daniesta@gmail.com

ORCID ID: https://orcid.org/0000-0002-0741-6776

MARÍLIA MATOS GONÇALVES, Dra. | Dra. Universidade Federal de Santa catarina - UFSC - Curso: Design | Endereço: Av. Mauro Ramos, 1250 - ap. A4 12. Centro, Florianópolis - SC CEP: 88020-302, Brasil. | e-maill: marilinhamt@gmail.com

ORCID ID: https://orcid.org/0000-0002-2541-300X

CRISTIANO ALVES, Dr. | Universidade Federal de Santa catarina - UFSC - Curso: Design | Endereço: R. Santos Saraiva, 739 Apto 101 - Estreito - Florianópolis/SC - 88070-100, Brasil. | e-maill: cralvesdesign@gmail.com

\section{COMO CITAR ESTE ARTIGO}

MARTINS, Taynara Oliveira; ALVES, Daniela Estaregue; GONÇALVES, Marília Matos; ALVES, Cristiano. Pesquisa E Desenvolvimento De Uma Coleção De Moda Slow Fashion. MIX Sustentável, [S.I.], v. 7, n.

1, p. 19-32, dez. 2020. ISSN 24473073. Disponível em:<http://www.nexos.ufsc.br/index.php/mixsustentavel>. Acesso em: dia mês. ano. doi:https://doi. org/10.29183/2447-3073.MIX2020.v7.n1.19-32. 
